\title{
A Brief Review of Die Sinking Electrical Discharging Machining Process towards Automation
}

\author{
M. M. Pawade* , S. S. Banwait \\ Department of Mechanical Engineering, National Institute of Technical Teachers Training and Research, Sector- 26, Chandigarh, India \\ *Corresponding author: mmpawade@gmail.com
}

Received April 15, 2013; Revised April 24, 2013; Accepted April 26, 2013

\begin{abstract}
Electrical Discharge Machine (EDM) is especially used for the manufacturing of 3-D complex geometry and hard material parts that are extremely difficult-to-machine by conventional machining processes. In this paper authors have reviewed the research work carried out in the development of die-sinking EDM within the past decades for the improvement of machining characteristics such as Material Removal Rate (MRR), Surface Roughness (SR) and Tool Wear Ratio (TWR). In this review various techniques reported by EDM researchers for improving the machining characteristics have been categorized as process parameters optimization, multi spark technique, powder mixed EDM, servo control system and pulse discriminating. At the end, flexible machine controller is suggested for Die Sinking EDM to enhance the machining characteristics and to achieve high-level automation. Thus, die sinking EDM can be integrated with Computer Integrated Manufacturing (CIM) environment as a need of agile manufacturing systems.
\end{abstract}

Keywords: electrical discharge machining, material removal rate, surface roughness, tool wear ratio and automation

\section{Introduction}

Electrical Discharge Machining (EDM) is a nonconventional process. EDM originally observed by English Scientist Joseph Priestly in 1770. At early stage of development EDM was very imprecise and riddled with failures. Further two Russian scientists, Dr. B.R. Lazarenko and Dr. N.I. Lazarenko in 1943, developed EDM process. Also they invented the relaxation circuit and a simple servo controller too, that helped maintain the gap width between the tool and the work-piece. Further research is contributed in the development of EDM process for the improvement of machining characteristics in the direction of material removal rate and surface finish.

\subsection{EDM Working Principle}

EDM is thermal erosion process where controlled electric spark discharge takes place between tool and work-piece to have the eroding effect on work-piece to form a replica of tool on work-piece. As there is no mechanical contact between both electrodes during whole process and erosion is produced by electrical discharge. Electrical conductivity of electrode and work-piece is the basic requirement of this process. So, electrical resistivity of both electrodes must lie between 100 and $300 \Omega \mathrm{cm}$ $[1,2]$. This electric sparking process is carried out in a dielectric liquid or in gas $[3,4,5,6]$. Dielectric mush have low-viscosity, high dielectric strength, quick recovery after breakdown, effective quenching/cooling and flushing ability $[7,8,9,10,11]$. Flushing methods are classified into four main categories: immersion flushing, jet flushing, normal flow and reverse flow.

Breakdown of dielectric is initiated by moving the tool electrode towards (near the) work-piece and forming a plasma channel [12]. The location of breakdown is generally between the closest points of the electrode and of the work-piece. Due to spark breakdown, voltage falls and current rises abruptly that causes numerous randomly ignited monodies charges, which forms the crater at spot of discharge on work piece. As plasma channel has been created due to ionization of dielectric this lead the conductivity of gap and because of applied current heat is generated around a range of 8000 to $20,000^{\circ} \mathrm{C}[13,14,15]$ at the crater spot. The size of a crater is determined by discharge energy, which can be set on the machine by setting the discharge current and the discharge duration $[16,17,18,19]$.

This will cause strong heating of the work piece material (but also of the tool electrode material), rapidly creating a small molten metal pool at the surface $[20,21,22]$. A small quantity of metal can even be directly vaporized, some of is flushed with dielectric in the form of debris and remaining will be re-solidify (recast layer/white layer) due to dielectric. The material removal rate is determined by the crater size and the frequency of crater generation [23], i.e. discharge energy and the frequency of discharges. Finally, the cavity produced in the work piece is approximately the replica of tool [24].

\section{Developments in EDM}


For review purpose this paper has been categorised in two major category. First, part deals with the developments in the field of EDM in last few decades and classified them in five major classes as : process parameter optimization, multi- spark techniques, powder mixed EDM, servo control system and pulse discrimination techniques. Final part of the paper explains the need of automation and the integration of existing die sinking EDM with the flexible machine controller to fulfill the today's need of agile manufacturing systems.

The main objective of EDM researchers has been high material removal rate (MRR) and better surface finish (SF) at lower tool wear ratio.

\subsection{Influencing Process Parameters}

EDM process not only depends on capacities of machine but also depends upon processing parameters. There are so many parameters that affects the EDM process, some of the major influencing process parameters like discharge voltage, frequency of current, gap between tool electrode \& work piece, ignition delay time, pulse on time, pulse off time, polarity, flushing type, properties of dielectric media, conductivity of electrodes, eroding area etc. All these process parameters play a vital role in deciding machining characteristics like surface finish, energy consumption and efficiency (MRR) of EDM process. Researchers have reported that most influencing process parameters are discharge current [25-35], pulse on time [25-31,33-35], pulse off time [25,26,28,30,34,35] and dielectric liquid pressure [29,31,32,36].

\subsection{Multi Spark}

Conventional EDM has only one discharge point for each pulse. To obtain multi spark in single pulse tool electrode was divided into two parts [37,38,39] and multi parts $[40,42,43]$. These electrodes were electrically insulated from each other and connected to the pulse generator for getting multi/parallel spark in a single pulse. Experimentally it was analyzed that in single pulse, conventional EDM gives one spark, whereas multi spark EDM gives multiple sparks depending upon division of electrodes in number of parts. Power consumption for conventional EDM as well as multi spark EDM is same but in multi spark EDM the power generated in gap is ' $n$ ' times the number of electrode part as compared to conventional EDM within a single pulse. Due to this surface finish [40,43] and MRR [39,40,43] is higher in multi spark EDM, at low energy consumption as compared to conventional EDM [39].

\subsection{Powder Mixed EDM}

As mentioned in section 1.1, white layer is hard and contain micro-cracks, caused by high tensile residual stresses exceeding the ultimate strength of the material $[26,28]$. This surface imperfection further reduces the fatigue, wear and corrosion resistance of Electrical Discharge Machined components [44,45,46,47,48]. Instead of post-machining processes to remove damaged surface layer and to restore the surface properties, powder mixed electrical discharge machining (PMEDM) [49] is suggested. In PMEDM the powder of aluminum (Al) [50,51,52,56,57,61,62,66,67], chromium (Cr) [52,53,66,67], graphite (Gr) [55,56,62], copper $(\mathrm{Cu})$ [52,57], and silicon (Si) $[54,56,62,66,67]$ were mixed with dielectric media and experimentation were performed. It was reported that conductive and inorganic oxide particles in the powder mixed dielectric increase the MRR [51,52,58,59,60,61] and improve the mirror-like [52,61,62,63,64,65] surface quality of the work-piece. It was also observed that hardness, abrasion and corrosion resistance of the machined surface improved significantly [56,66,67]. Size of powder particle, quantity of powder and type of dielectric media also plays vital role in machining [52].

\subsection{Servo Control}

Servo control is one of the most important control device for EDM process as it regulates the dimension of discharge gap that drives the machining performance and stability. It is not necessary to get healthy spark for two successive pulses even after maintain a constant discharge gap between electrodes. This is may be because of peaks and valleys on work piece surface, debris in dielectric that changes its gap conductive property. An adaptive control system $[68,69,70,71]$ maintains a desired gap that gives healthy spark, prevent harmful arcing and short circuit. Further [72,73,74] a new optimized adoptive control system was developed that not only detect undesirable machining conditions in advance but also take appropriate preventive actions before the situations really occur. Because of poor flushing condition debris creates an arcing between the electrodes as observed by Rajurkar and Wang $[75,76,77,78]$ and proposed model reference adaptive control system. In this system, on-line optimization software with new servo control interface circuit was developed on the base of model reference control theory. Self- tuning adaptive servo control system $[79,80,81]$ with feedback signal from EDM, was developed. This has better control performance of stochastic EDM process with good flushing system. To suppress the process noise disturbance in control system, EDM jumping proposed [82] with self -tuning controller[83]. On-line adjustment of all controllable parameters in EDM is still difficult due to the stochastic and dynamic nature of EDM. Still skilled machine operators are required to handle the EDM. Researchers [84,85,86,87] combine the different technique (fuzzy, ultrasonic vibration, pulse generator and servo feed control system) in adaptive controller for improvement of machine efficiency (MRR). Hayakawa et. al [88] was developed a new on-line gap measurement and control system with the help of EDM oil (dielectric) pressure. This minimized short-circuiting and debris flashing problem in EDM process.

\subsection{Pulse Discriminating}

EDM pulse is generally classified into several types they are, open pulse, spark pulse, arc pulse, short pulse, and off pulse $[89,90]$. For material removal, sparking pulse is required which give better surface finishing than other pulse type [91,92]. Whereas, arc and short pulses gives rough surface finish and EDM gets unstable caused by concentration of conductive particles between tool and work-piece gap [93], this machining condition is harmful. In order to over come from such circumstances a skilled operator is required to take a corrective action to stable the 
machine by adopting proper corrective measures. Further different online controllers were developed; polynomial function based Abductive network [89,94], pulse discriminating type analyser [95], radio frequency analyser [96,97], neutral network base [90,98], fuzzy base pulse discriminator system $[99,100]$ and digital signal procesing base [101]. These controllers identifies EDM process pulses and discriminates it and take proper corrective measures to stabilise the machine.

\subsection{Optimisation}

Usually machining parameters are determined by operator experience or handbook values. However, this does not ensure that the selected machining parameters result in optimal or near optimal machining performance. To overcome this, most influencing EDM process parameters were optimized to achieve low tool wear ratio and better surface finish with high efficiency (MRR). Researchers have performed experimentations on different combinations of tool and work-piece materials for the generation of data. Collected data based on specific applications were used for building a model with the help of Fuzzy Logic [102,103,104], Taguchi method [102,105,106,107,108], Neural Network [109-116], ANFIS [110,117-119], Design of Experiments [105,108,115,120-123], ANOVA [105,106,122,124], Genetic Algorithm [111,112,114,115,116] and hybrid techniques. Confirmation experiments were conducted to validate these models and process parameters were optimized for predicting the desired machining characteristics. All these models are electrode (tool and work-piece) material and machine dependent.

\section{Need for Automation}

A case study presented by Zeng et al. [125] where a mobile phone mould making industry uses 4500 to 7500 electrodes simultaneously for different cavity of mould. Each cavity requires rough, semi finish and finish operations, which in turn required three different tools. Machine operator has to perform variety of task simultaneously like machining parameters feeding, tool off set, editing of the programs, tool changing and so on. To handle such situations skilled operators are needed and to avoid the human error under such circumstances automated system is essential that can replace human task.

EDM survey [126] has discussed some typical issues which still require special attention to make integration of Die Sinking EDM for manufacturing systems. Authors $[127,128]$ have proposed the concept of EDM integration with CIM environment. Further Rajurkar and Wang [129] emphasized on the integration of EDM into future agile manufacturing systems which requires the EDM control system to have capabilities of high level automation and ability to share $\mathrm{CAD} / \mathrm{CAM}$ resources with remote EDM system and other remote manufacturing facilities.

The usage of die sinking EDM is increasing in manufacturing industries. Performance of die sinking EDM depends upon the skill of operator. To eliminate the skill operator's dependancy there is a need to develop a data base of EDM process parameters. Chakrabarti et al. [130] has attempted the design and implementation of a minimal managment information system(MIS) for handling AWJM, EDM and WEDM data which can be extended with suitable design enhancements to handle different manufacturing systems logically by interacting with the end user. Author has also emphasized the need for development of MIS for other non conventional machining process. For development of MIS, statistical data would be generated by carrying out extensive experimentation on different combinations of tool electrode - workpiece materials. Further from these data, optimized process parameters like discharge current, pulse on time and pulse off time would be determined and validated. To feed these optimized process parameters from MIS to EDM, a controller is needed. To achieve the automation and to reduce the operators dependency, integration of flexible controller (PLC) with the existing die sinking EDM is proposed.

\section{Proposed Automated System}

Programmable logic controllers (PLCs) are used in every aspects of industry to expand and enhanced production. Where older automated system uses hundreds or thousands of relays, a single PLC can be programmed as a replacements. The functionability of the PLC has evolved over the years to include capabilities beyond typical relay control: sophisticated motion control, process control, distributive control systems, and complex networking have now been added to the PLCs list of functions. PLCs provide many benefits which includes increased reliability, more flexibility, lower cost, communication capability with other controllers/computers to perform functions as supervisory control, data gathering, monitoring devices and process parameters, faster response time and easy to troubleshoot.

Figure 1, depicts the schematic diagram of EDM-PLC interface of the proposed system.

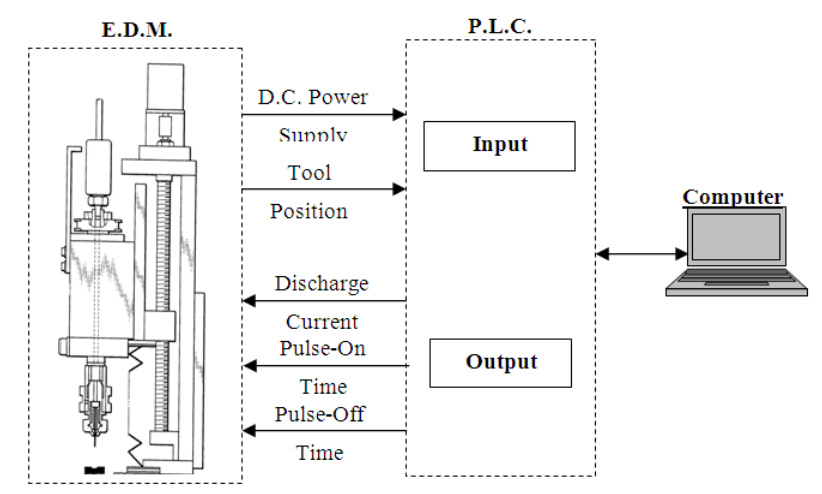

Figure 1. Schematic diagram of EDM-PLC interface

In this system, D.C. Power supply from capacitor bank and tool position of the existing die sinking EDM would act as an input to PLC. The most influencing process parameters of EDM, discharge current, pulse on and pulse off time will be fed to PLC through computer. This PLC is attached to computer serial port through RS232 cable, Supervisory Control and Data Acquisition (SCADA) system will used to communicate with PLC.

SCADA uses standard protocols for communication, thus distributing functionality across a LAN and WAN. A user screen will be designed using Human-Machine Interface, where a machine operator will select/feed the 
name of electrodes, required surface finish and finish depth. HMI will be linked to database of SCADA from where optimized EDM process parameters will be generated for three machining regime i.e. rough, semifinish and finish operations. Operator will be assigned a right to edit these parameters if required. These parameters can be fed to suggested controller at once by clicking a single button. Controller will switchover from rough machining regime to semi-finish and finally finish regime automatically depending upon incursion of tool in work piece material.

In posterior research, this stand alone die-sinking EDM will be interface with standard CAM/CAM software and CIM system.

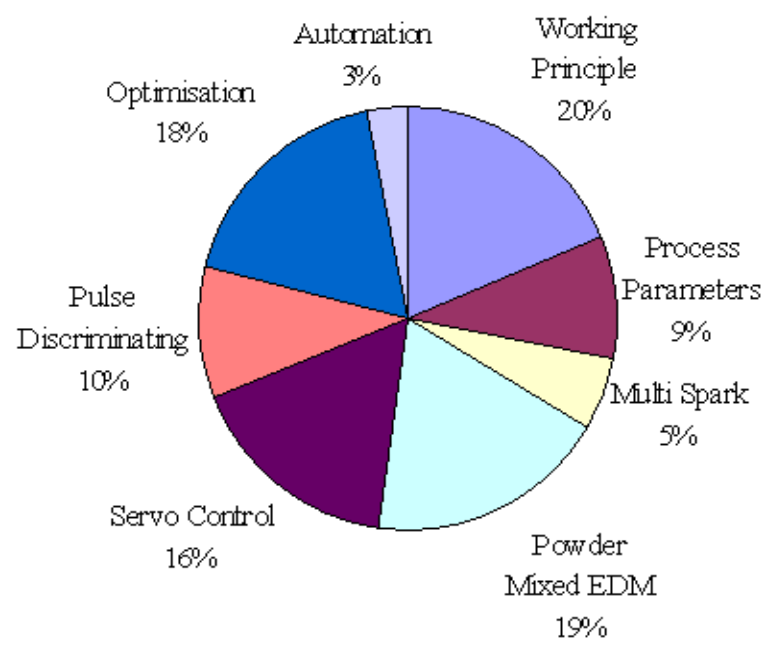

Figure 2. Distribution of Reviewed Research Publication

Figure 2 shows, the research done in various areas of EDM process for improving its performance measures. It is seen that $20 \%$ of the surveyed papers describes the working principle of EDM, $19 \%$ contributed towards addition of metal powders in dielectric, $18 \%$ work focused on process parameter optimization, $16 \%$ work emphasized on servo control, $10 \%$ on pulse discrimination and $5 \%$ on multi-spark for enhancing the performance of the machine. It is clearly seen that only $3 \%$ of the surveyed work attempted towards automation of EDM process. Hence there is a need to reduce the operators dependency and interface the existing die siking EDM with a flexible machine controller so that it can be integrated with CIM environment as need of agile manufacturing.

\section{Concluding Remarks}

Author have conducted a review of published work in past few decades and it is observed that majority of research have been made in the direction for improving the performance measures in terms of MRR and SR with the help of multi-spark technique, powder mixed EDM, servo controller developments, pulse discriminating system and optimization of parameters. As shown in Figure 2 very few attempts have been made to develop high level automation for die sinking EDM.

Authors suggested a new PLC based flexible controller for conventional die sinking EDM to achieve

- High level of automation.

- Sharing of CAD/CAM resources.
- Remote operation of EDM.

- EDM -Interface with other manufacturing facilities / network.

- Reduce operator dependency.

- Higher MRR with better SR.

\section{References}

[1] N.L. Mordecai, T.C. Lee and J. Huddleston, "Developments in spark erosion of ceramics", Br. Ceramics Trans., 94 (1), 1995, pp. 21-24.

[2] J.H. Zhang, T.C. Lee and W.S. Lau, "Study on the electrodischarge machining of a hot pressed aluminum oxide based ceramic", Journal of Materials Processing Technology, 63, 1997, pp. 908-912.

[3] Kunieda M. and Yoshida M., "Electrical Discharge Machining in Gas", Annals of the CIRP, 46/1, 1997, pp. 143-146.

[4] M. Kunieda and C. Furudate, "High Precision Finish Cutting by Dry WEDM", Annals of the CIRP, 50/1, 2001, pp. 121-124.

[5] M. Kunieda, Y. Miyoshi, T. Takaya, N. Nakajima, Z. Yu and M. Yoshida, "High Speed 3D Milling by Dry EDM, Annals of the CIRP, 52/1, 2003, pp. 147-150.

[6] C. Furudate and M. Kunieda, "Gap Phenomena in Dry WEDM", Denki-Kakou-Gijutsu (in Japanese), 26/83, 2002, pp. 21-27.

[7] Y.S. Wong, L.C. Lim and L.C. Lee, "Effects of Flushing on Electro-Discharge Machined Surfaces", Journal of Materials Processing Technology, 48, 1995, pp. 299-305.

[8] L.H. Godinho and C.F. Noble, "The Use of Water as Interelectrode Medium in Pulsed EDM", Proceedings of the Fifth International Symposium for Electro-machining, ISEM 6, 1977, pp. 63-67.

[9] T. Masuzawa, "Machining Characteristics of EDM Using Water as a Dielectric Fluid", Proceedings of the Twenty-Second Machine Tool Design and Research Conference, 1981, pp. 441-447.

[10] S. Tariq Jilam and P.C. Pandey, "Experimental Investigations Into the Performance of Water as Dielectric in EDM", International Journal of Machine Tool Design and Research, Vol. 24/1, 1984, pp. $31-43$.

[11] T. Masuzawa and K. Tanaka, "Water-based Dielectric Solution for EDM", Annals of the CIRP, 32/1, 1983, pp. 119-122.

[12] Shankar Singh, S. Maheshwari and P. C. Pandey, "Some investigations into the electric discharge machining of hardened tool steel using different electrode materials", Journal of Materials Processing Technology, 149 (1-3), 2004, pp. 272-277.

[13] G. Boothroyd and A.K. Winston, "Non-conventional machining processes", Fundamentals of Machining and Machine Tools, Marcel Dekker, Inc, New York, 1989, pp. 491.

[14] J.A. McGeough, Electro discharge machining in Advanced Methods of Machining, Chapman \& Hall, London, 1988, pp. 130.

[15] B. Sen, N. Kiyawat, P. K. Singh, S. Mitral, J. H. Ykmd and P. Purkait, "Developments in Electric Power Supply Configurations for Electrical- Discharge -Machining (EDM)", IEEE, 2003, pp. 659-664.

[16] Y.S. Wong, M. Rahmana, H.S. Lima, H. Hanb and N. Ravi, "Investigation Of Micro-EDM Material Removal Characteristics Using Single RC-Pulse Discharges," Journal of Materials Processing Technology, 140, 2003, pp. 303-307.

[17] H.T. Lee and T.Y. Tai, "Relationship between EDM parameters and surface crack formation," Journal of Materials Processing Technology, 142, 2003, pp. 676-683.

[18] Y.H. Guu, and Max Ti-Kuang Hou, "Effect of machining parameters on surface textures in EDM of Fe-Mn-Al alloy," Materials Science and Engineering, 466, 2007, pp. 61-67.

[19] M. Kiyak and O. Cakir, "Examination of machining parameters on surface roughness in EDM of tool steel," Journal of Materials Processing Technology, 191, 2007, pp. 141-144.

[20] L.C. Lee, L.C. Lim, V. Narayanan and V.C. Venkatesh, "Quantification of surface damage of tool steels after EDM", International Journal of Machine Tools and Manufacturing, 28/4, 1988, pp. 359-372.

[21] H.T. Lee and T.Y. Tai, "Relationship between EDM parameters and surface crack formation," Journal of Materials Processing Technology, 142, 2003, pp. 676-683.

[22] J.C. Rebelo, A. Morao Dias, D. Kremer and J.L. Lebrun, "Influence of EDM Pulse Energy On The Surface Integrity of 
Martensitic Steels," Journal of Materials Processing Technology, 84, 1998, pp. 90-96.

[23] Y.F. Luo, "An Investigation Into The Actual EDM Off-Time In SEA Machining", Journal of Materials Processing Technology, 74, 1998, pp. 61-68.

[24] W. Konig, D.F. Dauw, G. Levy and U. Panten, "EDM-future steps towards the machining of ceramics", Annals of the CIRP, 37/2, 1988, pp. 623-631.

[25] P.V. Ramarao and M.A. Faruqi, "Characteristics of the surfaces obtained in electro-discharge machining”, Precision Engineering, 4/2, 1982, pp. 111-113.

[26] H.T. Lee, "Influence of EDM process parameters on surface defects and roughness", Chin. J. Mater. Sci., 28/4, 1996, pp. 270278.

[27] C.C. Wang, B.H. Yan, H.M. Chow and Y. Suzuki, "Cutting austempered ductile iron using an EDM sinker", Journal of Materials Processing Technology, 88/1, 1999, pp. 83-89.

[28] H.T. Lee and J.P. Yur, "Characteristic analysis on EDMed surfaces using Taguchi method approach", Materials and Manufacturing Process, 15 /6, 2000, pp. 781-806.

[29] S.H. Lee and X.P. Li, "Study of the effect of machining parameters on the machining characteristics in electrical discharge machining of tungsten carbide", Journal of Materials Processing Technology, 115/3, 2001, pp. 344-358.

[30] H.S. Halkaci and A. Erden, "Experimental investigation of surface roughness in electric discharge machining", $6^{\text {th }}$ Biennial Conference (ESDA 2002) Turkey, 2002, pp. 1-6.

[31] S.H. Lee and X. Li, "Study of the surface integrity of the machined work-piece in the EDM of tungsten carbide", Journal of Materials Processing Technology, 139/1-3, 2003, pp. 315-321.

[32] Y.H. Guu, H. Hocheng, C.Y. Chou, and C.S. Deng, "Effect of electrical discharge machining on surface characteristics and machining damage of AISI D2 tool steel", Material Science and Engineering Applications, 358/1-2, 2003, pp. 37-43.

[33] C. Cogun, B. Kocabas and A. Ozgedik, "Experimental and theoretical investigation of wor-kpiece surface roughness profile in EDM", J. Fac. Engg. Arch., 19, 2004, pp. 97-106.

[34] Y. Keskin, H.S. Halkaci and M. Kizil, "An experimental study for determination of the effects of machining parameters on surface roughness in electrical discharge machining", Int. J. Adv. Manufacturing Technology, 28, 2006, pp. 1118-1121.

[35] M. Kiyak and O. Cakir, "Examination of machining parameters on surface roughness in EDM of tool steel," Journal of Materials Processing Technology, 191/1-3, 2007, pp. 141-144.

[36] A. Ozgedik and C. Cogun, "An experimental investigation of tool wear in electric discharge machining", Int. J. Adv. Manufacturing Tech. 27/5-6, 2006, pp. 488-500.

[37] Suzuki K., Mohri N., Uematsu T. and Nakagawa T., "ED Truing Method with Twin Electrodes", Preprint of Autumn Meeting of JSPE (Japanese), 1985, pp. 575-578.

[38] Kubota M, Tamura Y and Okita T., "Electro-contact discharge dressing of metal bonded diamond grinding wheels using twin electrode system", Proceedings of International Symposium for Electro-machining, 1989, pp. 22-25

[39] Masanori Kunieda and Hideyuki Muto, "Development of MultiSpark EDM," Annals of the CIRP, Vol. 49/1, 2000, pp. 119-122.

[40] Fujimoto R., "The multi-circuit system electric discharge machining process", J Jpn Soc Electrical Machining Eng (Japanese), 3/6, 1969, pp. 1-6.

[41] N. Mohri, N. Saito, T. Takawashi and K. Kobayashi, "Mirror-like finishing by EDM", Proceedings of Machine Tool Design and Research Conference, 1985, pp. 329-336.

[42] M. Kunieda and H. Muto, "Development of multi-spark EDM", Annals of the CIRP, 49/1, 2000, pp.119-122.

[43] Fuzhu Han and Masanori Kunieda, "Development of Parallel Spark Electrical Discharge Machining," Precision Engineering, 28, 2004, pp. 65-72.

[44] J.C. Rebelo, A. Morao Dias, D. Kremer and J.L. Lebrun, "Influence of EDM Pulse Energy on the Surface Integrity of Martensitic Steels," Journal of Materials Processing Technology, 84, 1998, pp. 90-96.

[45] H.T. Lee and T.Y. Tai, "Relationship between EDM parameters and surface crack formation," Journal of Materials Processing Technology, 142, 2003, pp. 676-683.

[46] L.C. Lee, L.C. Lim, Y.S. Wong and H.H. Lu, "Towards a better understanding of the surface features of electro-discharge machined tool steels", Journal of Materials Processing Technology, 24, 1990, pp. 513-523.
[47] L.C. Lee, L.C. Lim, V. Narayanan and V.C. Venkatesh, "Quantification of surface damage of tool steels after EDM", Int. J. Mach. Tools Manuf., 28/4, 1988, pp. 359-372.

[48] L.C. Lee, L.C. Lim and Y.S. Wong, "Towards crack minimisation of EDMed surfaces", Journal of Materials Processing Technology, 32, 1992, pp. 45-54.

[49] H.K. Kansal, Sehijpal Singh and Pradeep Kumar, "Technology and research developments in powder mixed electric discharge machining (PMEDM)", Journal of Materials Processing Technology, 184, 2007, pp. 32-41.

[50] K. L. Wu, B. H. Yan, F. Y. Huang and S. C. Chen, "Improvement of surface finish on SKD steel using electro-discharge machining with aluminum and surfactant added dielectric", Inter. Journal of Machine Tools \& Manufacture, 45, 2005, pp. 1195-1201.

[51] C.P. Yu, W.C. Chen, S.W. Chang and C.C. Chang, "Effects of the concentration of suspended aluminum powder in dielectric fluid on EDM of carbide of tungsten's", Proceedings of Conference of Chinese Society of Mechanical Engineers, Taiwan, 1996, pp. 445450.

[52] C.H. Wang, Y.C. Lin, B.H. Yan and F.Y. Huang, "Effect of characteristics of added powder on electric discharge machining", J. Jpn. Inst. Light Met. 42, 2001, pp. 2597-2604.

[53] T. Tani, F. Fukazawa, N. Mohri and M. Okada, "Machining phenomena in EDM of insulating ceramics using powder suspended working oil”, ISEM Bilbao, 2001, pp. 388-392.

[54] P. Pecas and E.A. Henriques, "Influence of silicon powder mixed dielectric on conventional electrical discharge machining", Int. J. Mach. Tools and Manuf., 43, 2003, pp. 1465-1471.

[55] M.L. Jeswani, "Effects of the addition of graphite powder to kerosene used as the dielectric fluid in electrical discharge machining", Wear, 70, 1981, pp.133-139.

[56] H. Narumiya, N. Mohri, N. Saito, H. Otake, Y. Tsnekawa, T. Takawashi and K. Kobayashi, "EDM by powder suspended working fluid", Proceedings ISEM, 1989, pp. 5-8.

[57] A. Erden and S. Bilgin, "Role of impurities in electric discharge machining", Proceedings of International Machine Tool Design and Research Conference, London, 1980, pp. 345-350.

[58] W.S. Zhao, Q.G. Meng and Z.L.Wang, "The application of research on powder mixed EDM in rough machining", Journal of Materials Processing Technology, 129, 2002, pp. 30-33.

[59] Y.F. Tzeng and C.Y. Lee, "Effects of powder characteristics on electro discharge machining efficiency", Int. J. Adv. Manuf. Technol., 17, 2001, pp. 586-592.

[60] K. Furutani, A. Saneto, H. Takezawa, N. Mohri and H. Miyake, "Accretion of titanium carbide by electrical discharge machining with powder suspended in working fluid”, Precis. Engg., 25, 2001, pp. 138-144.

[61] B.H. Yan and S.L. Chen, "Characteristics of SKD11 by complex process of electric discharge machining using liquid suspended with aluminum powder", J. Jpn. Inst. Light Met., 58/9, 1994, pp. 1067-1072.

[62] Y.S. Wong, L.C. Lim, I. Rahuman and W.M. Tee, "Near-mirrorfinish phenomenon in EDM using powder-mixed dielectric", Int. J. Adv. Manuf. Technol., 79, 1998, pp. 30-40.

[63] Y.S. Wong, L.C. Lim, I. Rahuman and W.M. Tee, "Near-mirrorfinish phenomenon in EDM using powder-mixed", Journal of Material Processing Technology, 79, 1998, pp. 30-40.

[64] Y.F. Luo, Z.Y. Zhang and C.Y. Yu, "Mirror surface EDM by electric field partially induced", Annals of the CIRP, 34, 1988, pp. 179-181.

[65] N. Saito and N. Mohri, "Improvement of machined surface roughness in large area EDM", Journal of the Japan Society of Precision Engineering, 57/6, 1991, pp. 954-958.

[66] Q.Y. Ming and L.Y. He, "Powder-suspension dielectric fluid for EDM", Journal of Material Processing Technology, 52, 1995, pp. 44-54.

[67] B.H. Yan, Y.C. Lin, F.Y. Huang and C.H. Wang, "Surface modification of SKD 61 during EDM with metal powder in the dielectric", Materials Transactions, 42/12, 2001, pp. 2597-2604.

[68] K. P. Rajlurkar and S. M. Pandit, "Adaptive Control of EDM Technology and Research", Proc. of North American Manufacturing Research Conference, 1985, pp. 814.

[69] N. Saito and K. Kobayashi., "Adaptive Control of EDM", Mitsubishi-Denki-Engineer, 27, 1970, pp. 39-44.

[70] W. A. Hawkins, "Adaptive Control Optimizes EDM", Metalworking Production, 1971, pp. 32-34. 
[71] R. Snoeys, D.F. Dauw, and J.P. Kruth, "Survey of Adaptive Control in Electro Discharge Machining," Journal of Manufacturing Systems, 2/2, 1983, pp. 147-164.

[72] J. P. Kruth, R. Snoeys and H. Van-Brussel, "Adaptive Control Optimization of the EDM Process Using Minicomputers", Computers- industry, 1/2, 1979, pp. 65-75.

[73] J. R. Crookall and T. W. Shaw, "Programmable Adaptive Control of EDM", Proc. International Conference MTDR, McMillan Press, 1980, pp. 339-343.

[74] R. Snoeyr, D. Dauw and J. P. Kruth, "Improved Adaptive Control System for EDM Pmcesses", Annals of the CIRP, 29/1, 1980, pp. 97-101.

[75] K. P. Rajurkar and W. M. Wang, "A New Model Reference Adaptive Control of EDM", Annals of the CIRP, 38/1, 1989, pp. 183-186.

[76] K. P. Rajurkar, "Adaptive Control Systems for EDM", SME International Conference on Non-Traditional Machining, Florida, EE-8P801. DO., 1989, pp. 1-13.

[77] W. M. Wang and K. P. Rajurkar, " New servo control interface and Model Reference Adaptive Control for EDM", North American Manufacturing Research Conference (NAMRC), 1989, pp. $281-286$.

[78] K. P. Rajurkar and W. M. Wang, "Real-Time Stochastic Model and Control of EDM", Annals of the CIRP, 39/1, 1990, pp. 187190.

[79] K. P. Rajurkar and W. M. Wang, "An Adaptive PI Controller for EDM Servo System with R.F Control", ASME Symposium on Flexible Automation., 2, 1992, pp. 1499-1505.

[80] M. Weck and J.M. Dehmer, "Analysis and Adaptive Control of EDM Sinking Process using the Ignition Delay Time and Fall Time as Parameter", Annals of the CIRP, 41/1, 1992, pp. 243-246.

[81] W. M. Wang, K. P. Rajurkar and K. Akamatsu, "Digital Gap Monitor and Adaptive Integral Control for Auto-Jumping in EDM", Transactions of the ASME, Journal of Engineering, 117, 1995, pp. 253-258.

[82] W.S. Zhao and T. Masuzawa., "Adaptive Control of EDM-JUMP with Self Tuning Approach", Bulletin of the Japan Society of Precision Engineering, 24/1, 1990, pp. 45-50.

[83] K. P. Rajurkar and W. M. Wang, "Improvement of EDM Performance with Advanced Monitoring and Control System", Journal of Manufacturing Science and Engineering, 119, 1997, pp. 770-775.

[84] Y. Zhang: J. Ying, Z. Chen and W. Chen, "The Research on the Self Adaptive Fuzzy Control System for Electric Discharge Machining", IEEE International Conference on Intelligent Professing Systems, 1, 1997, pp. 364-367.

[85] J.H. Zhang, H. Zhang, D.S. Su, Y. Qin, M.Y. Huo, Q.H. Zhang and L. Wang, "Adaptive Fuzzy Control System of a Servomechanism for Electro-Discharge Machining with Ultrasonic Vibration", Journal of Material Processing Technology, 129, 2002, pp. 45-49.

[86] J.H. Zhang, T.C. Lee, W.S. Lau and B. X. Ai, "Spark erosion with ultrasonic frequency", Journal of Materials Processing Technology, 68, 1997, pp. 83-88.

[87] F. Hana, S. Wachi and M. Kunieda, "Improvement Of Machining Characteristics Of Micro - EDM Using Transistor Type Isopulse Generator And Servo Feed Control”, Precision Engineering, 28, 2004, pp. 378-385.

[88] S. Hayakawa, M. Takahashi, F. Itoigawa and T. Nakamura, "Study on EDM Phenomena with In-Process Measurement of Gap Distance", Journal of Materials Processing Technology, 149, 2004, pp. $250-255$.

[89] H. S. Liu and Y. S. Tarng, "Monitoring Of The Electrical Discharge Machining Process By Abductive Networks," Int J. Adv. Manuf. Technol., 13, 1997, pp. 264-270.

[90] J.Y. Kao and Y.S. Tarng, "A Neutral-Network Approach for the On-Line Monitoring of the Electrical Discharge Machining Process", Journal of Material Processing Technology, 69, 1997, pp. $112-119$

[91] C. Cogun, "A technique and its application for evaluation of material removal contributions of pulses in electrical discharge machining", International Journal of Machine Tools and Manufacture, 30/1, 1990, pp. 19-31.

[92] L.C. Lee, L.C. Lim, V. Narayanan and V.C. Venkatesh, "Quantification of surface damage of tool steels after EDM", International Journal of Machine Tools and Manufacture, 28/4, 1988, pp. 359-372.
[93] M. Junkar and J. Valentincic, "Towards intelligent control of electrical discharge machining", Journal of Manufacturing Systems 29/5, 1999, pp. 453-457.

[94] R. Snoeys, D. F. Dauw and J. P. Kruth, "Improved adaptive control system for EDM processes", Annals of the CIRP, 29/1, 1980, pp. $97-101$.

[95] D. F. Dauw, R. Snoeys and W. Dekeyser, "Advanced pulse discriminating system for EDM process analysis and controls", Annals of the CIRP, 32/2, 1983, pp. 541-549.

[96] S. K. Bhattacharyya and M. F. E1-Menshawy, "Monitoring the EDM process by radio signals", International Journal of Production Research, 16/5, 1978, pp. 353-363.

[97] S. K. Bhattacharyya and M. F. El-Menshawy,"Monitoring and controlling the EDM process", ASME Journal of Engineering for Industry, 102, 1980, pp. 189-194.

[98] J.Y. Kao and Y.S. Tarng, "A neural-network approach for the online monitoring of the electrical discharge machining process", Journal of Materials Processing Technology, 69, 1997, pp. 112119.

[99] Y.S. Tarng, C.M. Tseng and L.K. Chung,"A Fuzzy Pulse Discriminating System For Electrical Discharge Machining”, Int. J. Machine Tools and Manufacture, 37/ 4, 1997, pp. 511-522.

[100] T. Kaneko and T. Onodera, "Improvement in Machining Performance of Die-Sinking EDM by using Self-adjusting Fuzzy Control", Journal of Materials Processing Technology, 149/1, 2004, pp. 204-211.

[101] Yih-Fang Chang, "DSP-Based Ignition Delay Monitor and Control of an Electro- Discharge Machining Process", Intelligent Automation and Soft Computing, 13/2, 2007, pp. 139-151.

[102] J.L. Lin, K.S. Wang, B.H. Yan and Y.S. Tarng, "Optimization of electrical discharge machining process based on the Taguchi method with fuzzy logics", Journal of Material Processing Technology, 102, 2000, pp. 48-55.

[103] J.L Lin and C.L. Lin, "The use of grey-fuzzy logic for the optimization of the manufacturing process", Journal of Material Processing Technology, 160, 2005, pp. 9-14.

[104] Oguzhan Yilmaz, Omer Eyercioglu and Nabil N.Z. Gindy, "A user friendly fuzzy-based system for the selection of electro discharge machining process parameters", Journal of Materials Processing Technology, 172, 2006, pp. 363-371.

[105] H.Ramasawmya and L. Blunt, "Effect of EDM process parameters on 3D surface topography", Journal of Material Processing Technology, 148, 2004, pp. 155-164.

[106] P. Narender Singh, K. Raghukandan, M. Rathinasabapathi and B.C. Pai, "Electric Discharge machining of $\mathrm{Al}-10 \% \mathrm{SiCp}$ as-cast metal matrix composites", Journal of Material Processing Technology, 155, 2004, pp. 1653-1657.

[107] S.S. Mahapatra and Amar Patnaik, "Parametric optimization of Wire Electric Discharge Machining process using Taguchi Method", Journal of Brazil Soc. of Mech. Science and Engineering, XXVII/4, 2006, pp. 422-429.

[108] P. Matoorian, S. Sulaiman and M.M.H.M. Ahmad, "An experimental study of optimization of electric discharge turning process", Journal of Materials Processing Technology, 204, 2008, pp. 350-356.

[109] Kuo-Ming Tsai and Pei-Jen Wang, "Comparison of neural network models on material removal rate in electric discharge machining", Journal of Material Processing Technology, 117, 2001, pp. 111-124.

[110] Kuo-Ming Tsai and Pei-Jen Wang, "Prediction of surface finish in electric discharge machining based upon neural network models", International Journal of Machine Tools and Manufacture, 41, 2001, pp. 1385-1403.

[111] Qing Gao, Qin-he Zhang, Shu-peng Su and Jian-hua Zhang, "Parameter optimization model in electric discharge machining process”, Journal of Zhejiang University Science, 9/1, 2008, pp. 104-108.

[112] G. K. Mohan Rao, G. R. Janardhana, D. H. Rao and M. S. Rao, "Development of Hybrid Model and optimization of metal removal rate in electric discharge machining using artificial neural network and genetic algorithms", ARPN Journal of Engineering and Applied Science, 3/1, 2008, pp. 19-30.

[113] A. P. Markopoulos, D. E. Manolakos and N. M. Vaxevanidis, "Artificial neural network models for the prediction of surface roughness in Electrical discharge machining", Journal of Intelligent Manufacturing, 19, 2008, pp. 283-292.

[114] Kesheng Wang, Hirpa L. Gelgele, Yi Wang, Qingfeng Yuan and Minglung Fang, "A hybrid intelligent method for modeling the 
EDM process", International Journal of Machine Tools and Manufacture, 43, 2003, pp. 995-999.

[115] D. Mandal, S. K. Pal and P. Saha, "Modeling of electrical discharge machining process using back propagation neural network and multi-objective optimization using non-dominating sorting genetic algorithm-II", Journal of Materials Processing Technology, 186, 2007, pp. 154-162.

[116] Qing Gao, Qin-he Zhang, Shu-peng Su and Jian-hua Zhang, "Parameter optimization model in electrical discharge machining process", Journal of Zhejiang University Science, 9/1, 2008, pp. 104-108.

[117] Ulas Caydas, Ahmet Hascalik, Sami Ekici, "An adaptive neurofuzzy inference system (ANFIS) model for wire-EDM", Expert Systems with Applications, 36, 2009, pp. 6135-6139.

[118] S. Kumanan, C.P. Jesuthanam, R. Ashok Kumar, "Application of multiple regression and adaptive neuro-fuzzy inference system for prediction of surface roughness", International Journal of Advanced Manufacturing Technology, 35, 2008, pp. 778-788.

[119] Shibendu Shekhar Roy, "Design of adaptive neuro-fuzzy inference system for prediction surface roughness in turning operation", Journal of Scientific and Industrial Research, 64, 2005, pp. 653659.

[120] Puertas, C.J. Luis and L. Alvarez, "Analysis of the influence of EDM parameters on surface quality, MRR and EW of WC-Co", Journal of Material Processing Technology, 153, 2004, pp. 10261032.

[121] C.J. Luis and I. Puertas, "Methodology for developing technological tables used in EDM process of conductive ceramics", Journal of Material Processing Technology, 189, 2007, pp. 301309.
[122] R. Karthikeyan, P.R. Lakshmi Narayanan and R.S. Naagarazan, "Mathematical modeling for electric discharge machining of aluminium-silicon carbide particulate composites", Journal of Materials Processing Technology, 87, 1999, pp. 59-63.

[123] Pei-Jen Wang and Kuo-Ming Tsai, "Semi-empirical model on work removal and tool wear in electrical discharge machining", Journal of Material Processing Technology, 114, 2001, pp. 1-17.

[124] S. Dhar, R. Purohit, N. Saini, A. Sharma and G. Hemath Kumar, "Mathematical modeling of electric discharge machining of cast Al-4Cu-6Si alloy-10 wt.\% SiCP composites", Journal of Materials Processing Technology, 194, 2007, pp. 24-29.

[125] H. Zeng, B. S. Lim, G. H. Phua, Z. Ding, L. Leng Aw, T. K. Tan Xiang $\mathrm{Li}$ and $\mathrm{K}$. M. Goh, "Electrode Verification and Management System for Automation of EDM Process in Mould Industry," Annual Conference of IEEE, 2005, pp. 474 - 479.

[126] K.H. Ho and S.T. Newman, "State of the art electrical discharge machining (EDM)", International Journal of Machine Tools and Manufacture, 43, 2003, pp. 1287-1300.

[127] M. DeVries, N.A. Duffine, J.P. Kruth, D.F. Dauw and B. Schumacher, "Integration of EDM within a CIM Environment", Annuls of the CIRP, 39/2, 1990, pp. 1-8.

[128] K. P. Rajurkar, "Technology and research in EDM", International Manufacturing Technology Conference, Chicago, MS90-428, 1990, pp. 1-13.

[129] K. P. Rajurkar and W. M. Wang, "Improvement of EDM Performance with Advanced Monitoring and Control systems," ASME, 119, 1997, pp. 770-775.

[130] S. Chakrabarti, S. Mitra and B. Bhattacharya, "Development of management information system as knowledge base model for machining process characterization", International Journal of Advanced Manufacturing Technology, 34, 2007, pp. 1088-1097. 